\title{
Marijuana Use and Health in Primary Care
}

\author{
Daniel Fuster, MD, PhD, Jeffrey H. Samet, MD, MA, MPH, and Richard Saitz, MD, MPH
}

Clinical Addiction Research and Education (CARE) Unit, Section of General Internal Medicine, Department of Medicine, Boston Medical Center and Boston University School of Medicine, Boston, MA, USA.

J Gen Intern Med 29(2):282

DOI: $10.1007 / \mathrm{s} 11606-013-2705-9$

(c) Society of General Internal Medicine 2013

$\mathrm{T}$ he Authors' Reply-We read with interest the letter by Chukwuemeka ${ }^{1}$ addressing our recently published research. $^{2}$

As stated in the limitations section of our paper, we agree that our sample might not be generalizable to all marijuana users. However, we believe that a sample identified by screening in primary care is important, given that prior studies have focused on other selected samples, like patients receiving treatment for addiction. ${ }^{3}$ Also, it seems unlikely that the associations between frequency of marijuana use and the outcomes of interest (health status, comorbidity, emergency department utilization and hospitalization) would differ in this population from others.

We agree that it is a possibility that patients not included in our study (because they were ineligible or because they refused to participate) could be systematically different from those included regarding some baseline characteristics other than the ones we checked (age, gender and frequency of marijuana use).

As noted in the discussion, we believe that a study using a comparison group of primary care patients that do not use drugs is needed. In spite of the fact that the interpretation of results with a reference category of "no drug use" would be easier, the absence of any dose response clearly reduces the likelihood that a causal association exists between frequency of marijuana use and the outcomes of interest.

Financial disclosure: This study was supported by funding from Award Number R01DA025068 from the National Institute on Drug Abuse and, in part, by the National Center for Research Resources (Award Number UL1RR025771).

Dr. Fuster is a postdoctoral grantee from the Spanish Ministry of Education/Fundación Española para la Ciencia y la Tecnología (EDU/3495/2010). Dr. Fuster was also funded by grants from the Ministry of Science and Innovation, Spain (grants RD06/001/0021, RD06/006/1014 and RD12/0028/0006) and the Ministry of Health (grant EC11-042).

Corresponding Author: Daniel Fuster, MD, PhD; Clinical Addiction Research and Education (CARE) Unit, Section of General Internal Medicine, Department of Medicine, Boston Medical Center and Boston University School of Medicine, 801 Massachusetts Avenue, 2nd floor (Room \#2022C), Boston, MA 02118-2335, USA (e-mail: Daniel.Fuster@bmc.org).

\section{REFERENCES}

1. Chukwuemeka O. Marijuana use and health in primary care. J Gen Intern Med. 2013.

2. Fuster D, Cheng DM, Allensworth-Davies D, Palfai TP, Samet JH, Saitz R. No detectable association between frequency of marijuana use and health or healthcare utilization among primary care patients who screen positive for drug use. J Gen Intern Med. 2013. doi:10.1007/ s11606-013-2605-z.

3. Arendt M, Munk-Jorgensen P, Sher L, Jensen So. Mortality among individuals with cannabis, cocaine, amphetamine, MDMA, and opioid use disorders: A nationwide follow-up study of Danish substance users in treatment. Drug Alcohol Depend. 2011;114(2-3):134-9. 